\title{
Loss of the Common "A" Determinant of Hepatitis B Surface Antigen by a Vaccine-induced Escape Mutant
}

\author{
Jennifer A. Waters, ${ }^{\star}$ Maureen Kennedy, ${ }^{\star}$ Pierre Voet, ${ }^{\star}$ Pierre Hauser, ${ }^{\star}$ \\ Jean Petre, ${ }^{\star}$ William Carman, ${ }^{\star}$ and Howard C. Thomas \\ * Department of Medicine, St. Mary's Hospital Medical School, Imperial College of Science and Technology, London University, \\ London W2 INY, United Kingdom; and ${ }^{\ddagger}$ SmithKline Beecham Biologicals S.A., B-1330 Rixensart, Belgium
}

\begin{abstract}
A previous study (Carman, W. F., A. R. Zanetti, P. Karayiannis, J. A. Waters, G. Manzillo, E. Tanzi, A. J. Zuckerman, and H. C. Thomas. 1990. Lancet. 336:325-329) demonstrated a variant hepatitis $B$ surface antigen (HBsAg) in a vaccinated child born to a hepatitis B virus-infected mother. A substitution of arginine for glycine at amino acid 145 in $\mathrm{HBsAg}$ was observed. In this study the effect of this substitution on the common "a" determinant of this protein, against which protective immunity is directed, is investigated. Using recombinant HBsAg with and without the amino acid substitution, the binding of monoclonal antibodies that recognize different epitopes of the "a" determinant, was shown to be destroyed by the presence of arginine at amino acid 145 . In convalescent and vaccinee sera, antibody binding to $\mathrm{HBsAg}$ was not inhibited by the variant $\mathrm{HBsAg}$. Immunization with the variant $\mathrm{HBsAg}$, although eliciting a high titer antibody that recognized the variant, produced a low titer of antibody recognizing the native protein. Studies in mice demonstrate that the immunogenicity of the variant protein is also substantially altered.

The data presented here demonstrate that this variant evades the known protective anti-HBs response and lends support to the suggestion that this mutation arose as the result of immune pressure. (J. Clin. Invest. 1992. 90:2543-2547.) Key words: monoclonal antibodies $\bullet$ variant antigen $\bullet$ antigenicity • immunogenicity $\bullet$ immunoassay
\end{abstract}

\section{Introduction}

Antibodies to the common "a" determinant of hepatitis B surface antigen ( $\mathrm{HBsAg})^{1}$ confer protection against infection with hepatitis B virus ( HBV) of all subtypes (1-4). Using monoclonal antibodies this determinant has been shown to be com-

Address correspondence to Dr. J. A. Waters, Department of Medicine, St. Mary's Hospital Medical School, London W2 1NY, United Kingdom. Dr. Carman's current address is Institute of Virology, Church Street, Glasgow G115 JR, United Kingdom.

Received for publication 19 February 1992 and in revised form 22 May 1992.

1. Abbreviations used in this paper: $\mathrm{HBsAg}$, hepatitis B surface antigen; HBV, hepatitis B virus.

J. Clin. Invest.

(C) The American Society for Clinical Investigation, Inc.

$0021-9738 / 92 / 12 / 2543 / 05 \quad \$ 2.00$

Volume 90, December 1992, 2543-2547 posed of a number of epitopes ( 5 ) and its tertiary structure has been shown to be important for its antigenicity $(6,7)$.

An important region of this determinant lies between amino acids 124 and 147. Replacement of the cysteines at amino acids 124 and 147 with serines or replacement of the proline at residue 142 of $\mathrm{HBsAg}$ by point mutation, destroys its antigenicity, demonstrating that these amino acids are essential for the display of full antigenicity of this region (8).

A variant of $\mathrm{HBV}$ has been described in a child born to an $\mathrm{HBV}$-infected mother. The child became HBsAg positive despite passive and active immunization at birth and the development of high titer anti-HBs. HBV-DNA from the child was sequenced in the region encoding amino acids 124-147 using the polymerase chain reaction. A point mutation from guanosine to adenosine at nucleotide position 587 which would result in an amino acid substitution from glycine to arginine at amino acid 145 of $\mathrm{HBsAg}$, was observed $(9,10)$. This variant was not present in the mother.

Monoclonal antibodies that bind to epitopes within the common " $a$ " determinant of HBV have been shown to bind to two cyclical peptide analogues of this region, containing amino acids 124-137 and 139-147, respectively (11). One of the antibodies (RFHBs 1), binding to peptide 124-137, has been shown to prevent infection with $\mathrm{HBV}$ in a susceptible chimpanzee (12). The HBsAg present in the serum of the child infected with the variant was analyzed using three of these monoclonal antibodies which bound respectively to the cyclical peptide analogues of amino acids 124-137 and 139-147 (10). There was a reduction in the binding of monoclonal antibodies of both specificities to the HBsAg present in the child's serum, suggesting that the mutation had resulted in a change affecting several epitopes in this region.

This study was undertaken to determine whether the change from glycine to arginine at amino acid 145 of $\mathrm{HBsAg}$ observed in the vaccinated child resulted in a loss of antigenicity of the $\mathrm{HBsAg}$ thereby allowing the mutant $\mathrm{HBV}$ to evade the humoral immune response.

\section{Methods}

Antigens. Strains of Saccharomyces cerevisiae expressing the wild-type ay (31A7), the wild-type ad (31Y6), or the mutant ay (31M5) HBsAg were prepared. The three expression cassettes contained the gene encoding the small surface antigen protein of the virus. In the mutant construction (31M5), a single site was modified to encode arginine instead of glycine at amino acid position 145 . In the two ay constructs, the expression plasmid used the Arg3 promoter (13) whereas the ad strain used the TDH3 promoter (14).

The strains were grown to high density in synthetic medium in $20 \mathrm{~L}$ fermentors. To exclude possible alteration of the antigenic properties by the purification procedures, the same extraction and purification scheme was applied to each antigen. Briefly, after disruption of the cells 
a

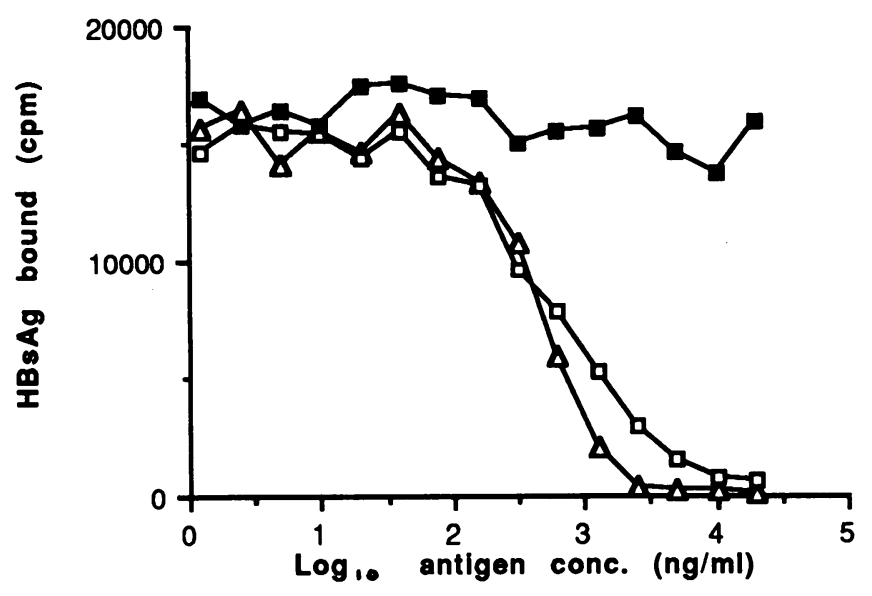

b

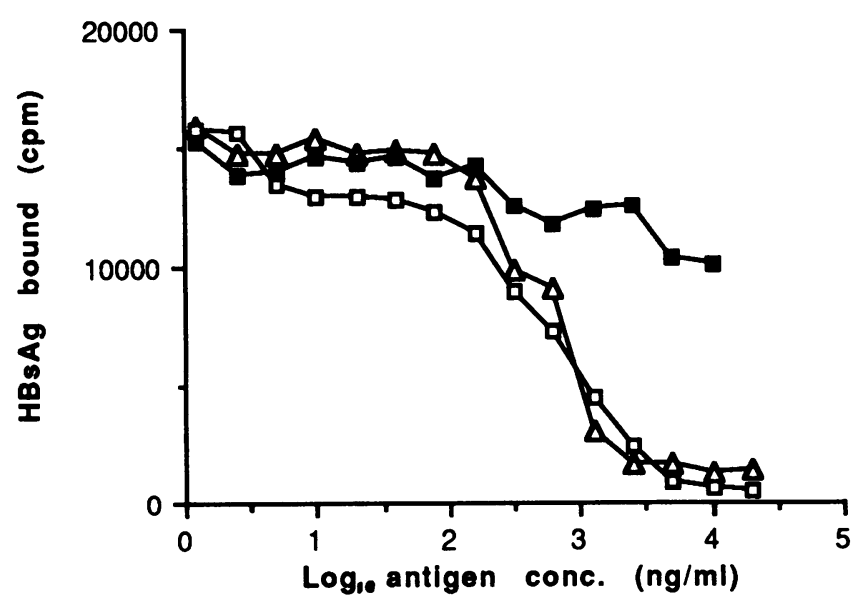

Figure 1. Binding of the anti-HBs in convalescent or vaccinee serum to the variant antigen. Specificity of binding of anti-HBs in $(a)$ vaccinees' sera and $(b)$ in convalescent sera. $\mathrm{HBsAg}$ used for inhibition: $\triangle$, 31Y6; $\square, 31 \mathrm{~A} 7$; $₫, 31 \mathrm{M} 5$.

and elimination of cell debris by centrifugation, $\mathrm{HBsAg}$ was extracted by adsorption to colloidal silica. Partially purified $\mathrm{HBsAg}$ was eluted as described by Van Wijnendaele and Simonet (15) using a buffer containing polysorbate (Tween) 20, but devoid of urea. The product was further purified by ultrafiltration, anion exchange chromatography, isopycnic caesium chloride ultracentrifugation, and size exclusion chromatography to obtain a purified solution in isotonic saline. The purity of the three antigen preparations was deemed superior to $95 \%$ by SDSpolyacrylamide gel electrophoresis under reducing conditions. Gels of the three preparations showed the typical $24-\mathrm{kD} \mathrm{HBsAg}$ major band with additional bands corresponding to dimeric and oligomeric forms (16).

Binding of anti-HBs in convalescent or vaccinee serum to the variant antigen. Limiting concentrations of pooled serum samples from either patients who were convalescent after an $\mathrm{HBV}$ infection or from volunteers who had been vaccinated with "Engerix B" (SB Biologicals, Rixensart, Belgium) were incubated with serial dilutions of the antigens for $2 \mathrm{~h}$ at $37^{\circ} \mathrm{C}$. The samples were then incubated overnight at room temperature with the $\mathrm{HBsAg}$ coated beads from the AUSAB kit (Abbott Laboratories, North Chicago, IL) and after washing, the residual anti-HBs bound to them detected with radiolabeled $\mathrm{HBsAg}$ also from the kit.
Table I. Binding. Characteristics of a Panel of Anti-HBs Monoclonal Antibodies that Are Directed Against the Group Specific Determinant " $A$ "

\begin{tabular}{|c|c|}
\hline \multicolumn{2}{|c|}{ Antibodies which bind to cyclical peptide $124-137$} \\
\hline RFHBs 1 & RFHBs 2 \\
\hline \multicolumn{2}{|c|}{ Antibodies which bind to cyclical peptide $139-147$} \\
\hline RFHBs 7 & RFHBs 4 \\
\hline \multicolumn{2}{|c|}{ Antibodies which do not bind to either peptide } \\
\hline RFHBs 6 & RFHBs 18 \\
\hline
\end{tabular}

Binding of monoclonal antibodies RFHBs 1 and 7 by variant antigen in the liquid phase. A limiting concentration of monoclonal antibodies RFHBs 1 and 7 were incubated with increasing concentrations of $31 \mathrm{~A} 7$ or $31 \mathrm{M} 5$ for $2 \mathrm{~h}$ at $37^{\circ} \mathrm{C}$. The samples were then incubated
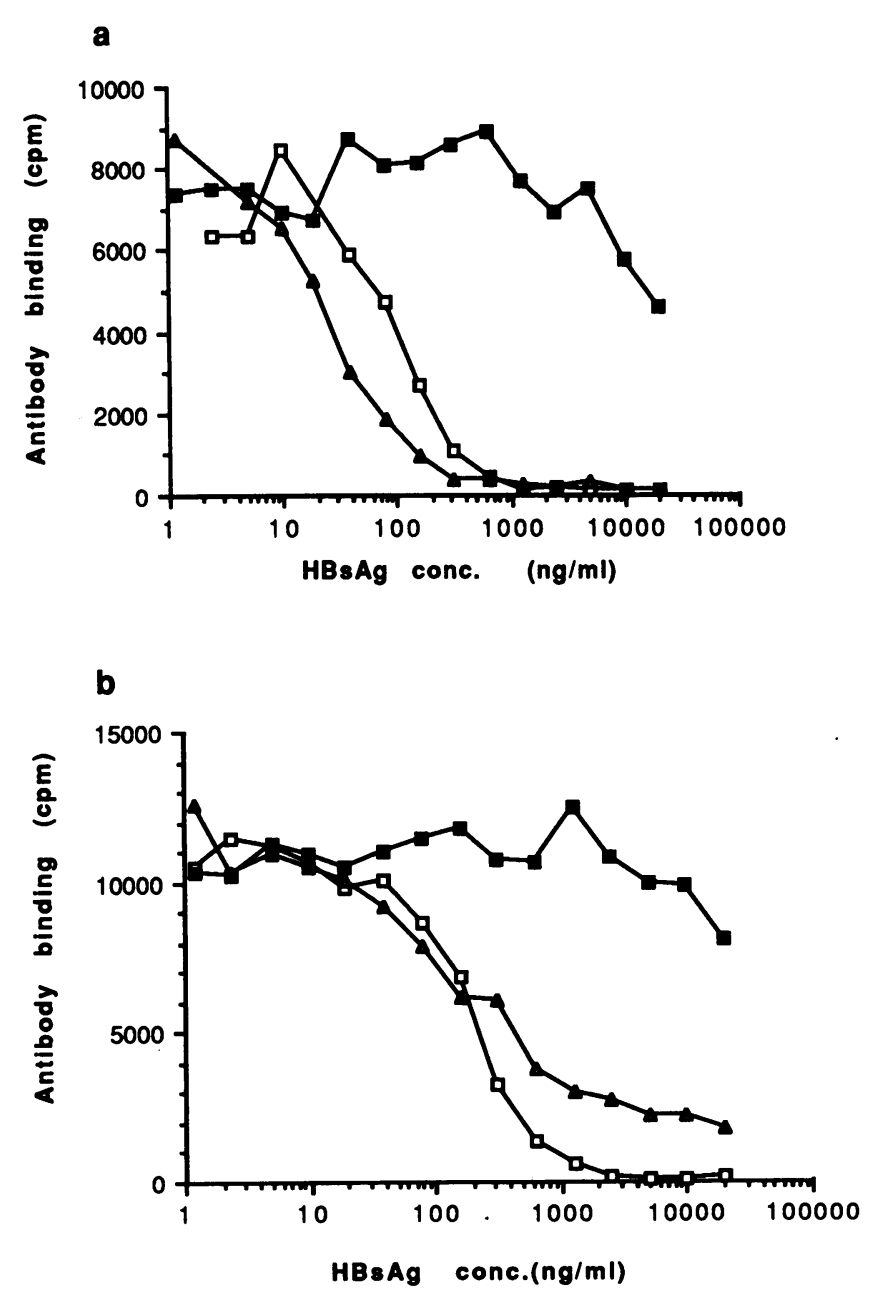

Figure 2. Binding of monoclonal antibodies RFHBs 1 and 7 by variant antigen in the liquid phase. (a) Binding of RFHBs 1 to HBsAg.

(b) Binding of RFHBs 7 to HBsAg. Recombinant HBsAg: $\square, 31 \mathrm{~A} 7$; ., 31M5; $\Delta, 31 \mathrm{Y} 6$. 
with beads from the AUSAB kit (Abbott Laboratories) overnight at room temperature. After washing the anti-HBs activity was detected with radiolabeled HBsAg also from the kit.

The binding of a panel of monoclonal antibodies that recognize different HBsAg epitopes to the variant antigen on the solid phase. Polystyrene beads were coated with either $31 \mathrm{~A} 7$ or $31 \mathrm{M} 5$ at an optimal concentration of $2 \mu \mathrm{g} / \mathrm{ml}$ and incubated with serial dilutions of purified monoclonal antibodies in 50\% newborn calf serum in PBS $(50 \%$ $\mathrm{NBCS}$ ) for $18 \mathrm{~h}$ at room temperature. After washing the bound antibody was detected by incubating with rabbit anti-mouse immunoglobulins labeled with horseradish peroxidase (Dakopatts, Copenhagen, Denmark) for $2 \mathrm{~h}$ at $37^{\circ} \mathrm{C}$. The reaction was visualized using $o$-phenylenediamine dihydrochloride.

Studies of the humoral response in mice after immunization with $31 \mathrm{~A} 7,31 Y 6$, or $31 \mathrm{M5}$. $10 \mathrm{Balb} / \mathrm{c}$ mice per group were injected intra- peritoneally with $1 \mu \mathrm{g}$ of protein of $31 \mathrm{~A} 7,31 \mathrm{M} 5$, or $31 \mathrm{Y} 6$ adsorbed onto aluminum hydroxide ( $20 \mu \mathrm{g}$ protein $/ 0.5 \mathrm{mg} \mathrm{Al}^{ \pm \pm \pm} /$) at days 0 and 30 . The animals were bled on day 30 and on day 45 . All assays were performed with pooled sera from each group. The AUSAB test was performed to measure total anti-HBs titers. The titers were expressed in milli-international units.

Specific antibody was measured by coating microtiter plates with the recombinant antigens and incubating these with serial dilutions of anti-HBs sera for $30 \mathrm{~min}$ at room temperature. After washing detection of antibodies was made using biotinylated anti-mouse immunoglobulin (RPN1021; Amersham International, Amersham, UK) for $30 \mathrm{~min}$ at $20^{\circ} \mathrm{C}$. This was detected with a streptavidin: biotinylated peroxidase complex (Amersham International). Binding curves were drawn and the titer that gave $50 \%$ of maximal binding was calculated for each group of animals ( $50 \%$ antibody titers). a Binding of RFHBs1

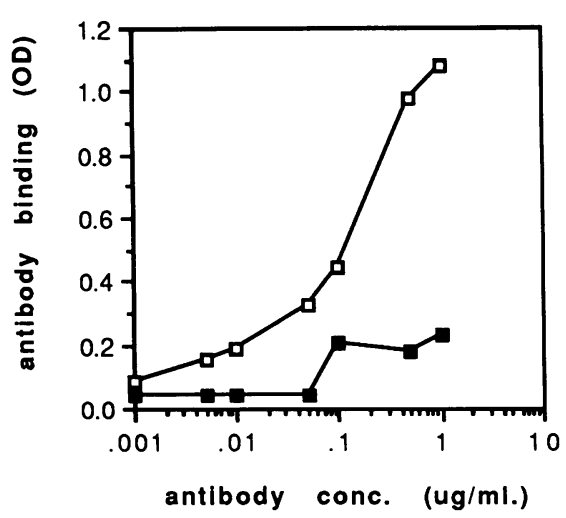

c Binding of RFHBs 7

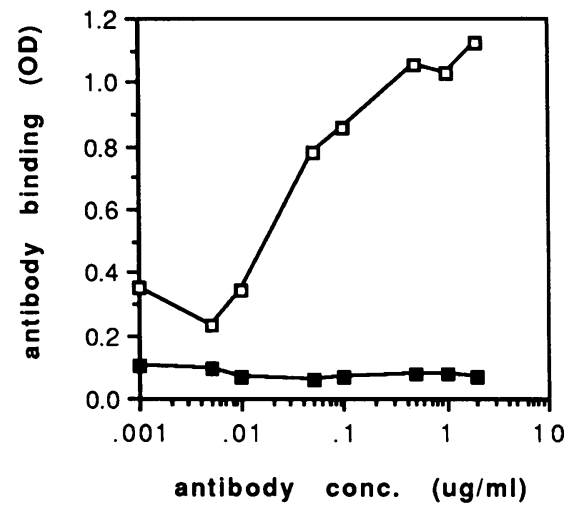

e Binding of RFHBs 18

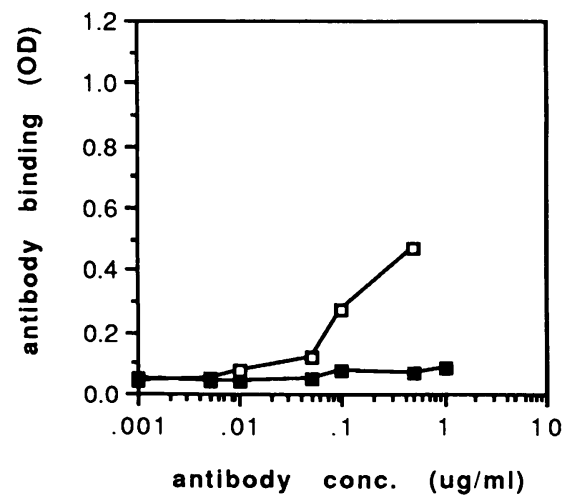

b Binding of RFHBs2

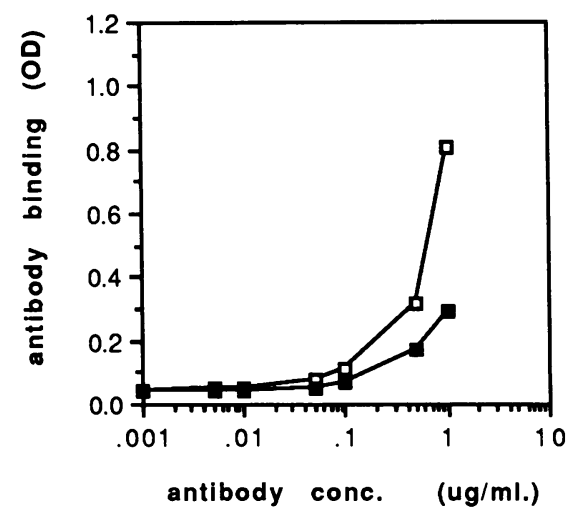

d Binding of RFHBs 4

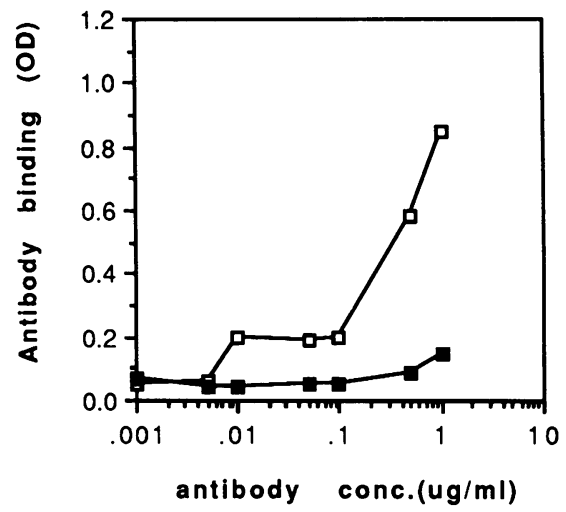

$f$ Binding of RFHBs 6

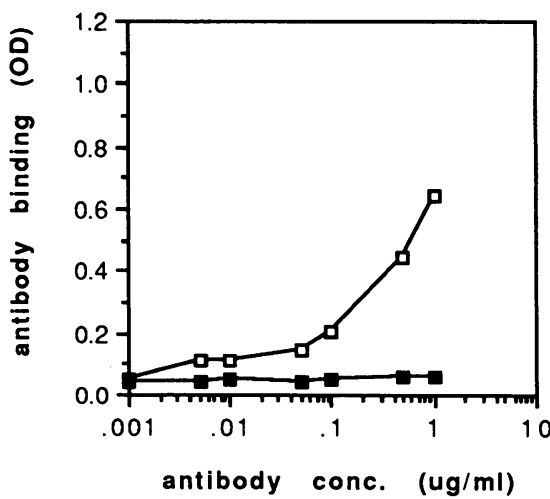

Figure 3. Binding of a panel of monoclonal antibodies that recognize different $\mathrm{HBsAg}$ epitopes to the variant antigen on the solid phase. Solid phase antigens: $\square, 31$ A 7 ;, 


\section{Results}

Binding of the anti-HBs in convalescent or vaccinees' serum to the variant antigen. The binding of anti-HBs antibodies in both convalescent sera and vaccinees sera to solid phase wild-type $\mathrm{HBs}$ Ag (AUSAB solid phase) were inhibited completely by the ay and the ad HBsAg (31A7 and 31Y6) particles. No inhibition was observed by the variant particles (31M5) in vaccinees' sera and only slight inhibition in convalescent sera (Fig. 1).

Inhibition of binding of monoclonal antibodies RFHBs 1 and 7 by variant antigen in the liquid phase. The binding specificities of the monoclonal antibodies used are summarized in Table I.

The binding of both RFHBs 1 and 7 was inhibited completely by the wild-type antigens $31 \mathrm{~A} 7$ and $31 \mathrm{Y} 6$ but not at all by the variant antigen $31 \mathrm{M} 5$ (Fig. 2).

The binding of a panel of monoclonal antibodies that recognize different $\mathrm{HBSAg}$ epitopes to the variant antigen on the solid phase. The two monoclonal antibodies that recognize the peptide 139-147 containing the amino acid 145, RFHBs 7 and 4, did not bind to the variant antigen. One of the antibodies, RFHBs 1, which recognizes the cyclical peptide analogue 124137 , also did not bind to the variant antigen. The other monoclonal antibody in this group, RFHBs 2 , did bind to the variant virus but at a 10 -fold higher concentration. The remaining two antibodies that do not bind to either peptide, RFHBs 18 and 6, did not bind to the variant antigen (Fig. 3).

Studies of the humoral response in mice after immunization with $31 A 7,31 Y 6$, or $31 M 5$. The anti-HBs response, as measured in the AUSAB assay, in Balb/c mice immunized with the wild-type antigens $31 \mathrm{~A} 7$ and $31 \mathrm{Y} 6$ was $>100$-fold greater than that raised by the variant antigen $31 \mathrm{M} 5$ after the second immunization (Table II).

The specific antibody titers measured using the recombinant antigens are illustrated in Fig. 4 and Table III. Immunization with ay subtype antigen $31 \mathrm{~A} 7$ raised four times more anti$31 \mathrm{~A} 7$ than anti-31M5 antibodies. In contrast, immunization with the variant antigen $31 \mathrm{M} 5$ elicited about five times more antibodies recognizing $31 \mathrm{M} 5$ than antibodies recognizing $31 \mathrm{~A} 7$.

\section{Discussion}

The antibody response to the common "a" determinant of $\mathrm{HBsAg}$ is known to confer protection against infection with

Table II. Total Anti-HBs Response in Balb/c Mice After Immunization with ay Subtype, ad Subtype, or Mutant ay Subtype HBsAg

\begin{tabular}{lcr}
\hline & \multicolumn{2}{c}{ Anti-HBs titer } \\
\cline { 2 - 3 } $\begin{array}{c}\text { Immunizing } \\
\text { antigen }\end{array}$ & $\begin{array}{c}30 \mathrm{~d} \text { after } \\
\text { first dose }\end{array}$ & $\begin{array}{r}15 \mathrm{~d} \text { after } \\
\text { second dose }\end{array}$ \\
\hline $\begin{array}{c}\text { ay subtype } \\
\text { (31A7) }\end{array}$ & 501 & 69113 \\
$\begin{array}{c}\text { Variant } \text { ay } \\
\text { (31M5) }\end{array}$ & 100 & 317 \\
$\begin{array}{c}a d \text { subtype } \\
\text { (31Y6) }\end{array}$ & 398 & 71663 \\
\hline
\end{tabular}

a

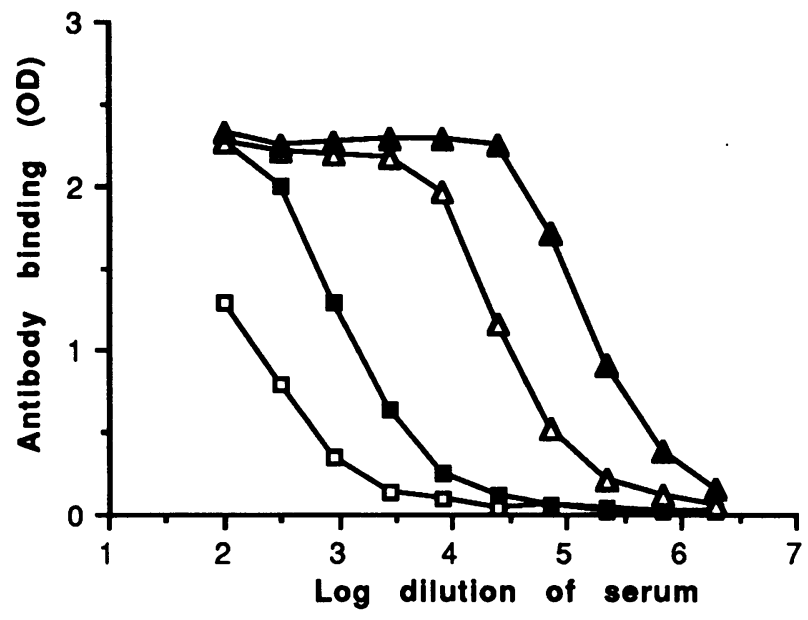

b

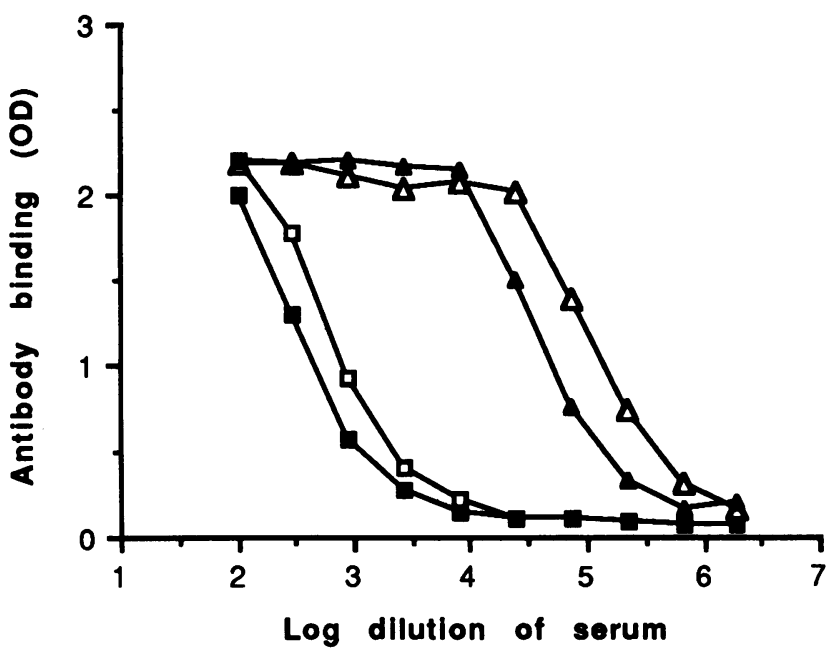

Figure 4. Specific antibody titers raised in mice after immunization with either 31A7 or 31M5. (a) Anti-31A7 antibodies. (b) Anti-31M5 antibodies. Immunizing antigen/time of bleed: $\square, 31 \mathrm{M} 5 / 30 \mathrm{~d} ; \mathbf{m}$, $31 \mathrm{~A} 7 / 30 \mathrm{~d} ; \Delta, 31 \mathrm{M} 5 / 45 \mathrm{~d} ; \Delta, 31 \mathrm{~A} 7 / 45 \mathrm{~d}$.

HBV. An important region of this determinant lies between amino acids 124 and 147 of the $\mathrm{HBsAg}$. A variant virus, which has a point mutation in the genome that results in an amino

Table III. Specificity of the Antibody Response in Mice after Immunization with either $31 A 7$ or $31 M 5$

\begin{tabular}{ccccc}
\hline \multirow{2}{*}{$\begin{array}{c}\text { Immunizing } \\
\text { antigen }\end{array}$} & \multicolumn{4}{c}{$50 \%$ antibody titers } \\
\cline { 2 - 5 } & Anti-31A7 $\mathrm{d}$ after first dose & Anti-31M5 & Anti-31A7 & Anti-31M5 \\
& & & & \\
$\begin{array}{c}\text { ay subtype } \\
\text { (31A7) }\end{array}$ & $1 / 1167$ & $1 / 392$ & $1 / 166439$ & $1 / 42398$ \\
$\begin{array}{c}\text { Variant } \text { ay } \\
(31 \mathrm{M} 5)\end{array}$ & $1 / 134$ & $1 / 788$ & $1 / 26935$ & $1 / 116305$ \\
\hline
\end{tabular}


acid substitution at position 145 of the HBsAg, has been described in a child who became HBV infected despite an adequate anti-HBs response (10). The amino acid arginine, which is substituted for glycine, is a much larger residue and is charged. As a result the hydrophobicity profiles of this region of the two antigens are quite different (10) and would be expected to affect the secondary and tertiary structure of the antigen. This amino acid substitution lies within an important region of the "a" determinant and so potentially alters the epitopes recognized by the protective immune response.

The recombinant HBsAgs used in this study were purified in the same way to exclude possible alteration of the antigenic properties by the purification procedures. Exposure to urea was avoided as this agent and other chaotropic salts can alter the structure of the HBsAg protein (16) while our previous studies have shown that the wild-type HBsAg spontaneously forms immunologically reactive particles (17). This study thus demonstrates that the substitution of arginine for glycine at amino acid 145 as the sole change in the protein, reduces the antigenicity of the HBsAg in a manner similar to that seen in the infected child. It is therefore likely that this change was the reason for the evasion of the host response. The first structural change responsible for the escape of HBV from the natural and vaccine-induced immune response is now established.

The anti-HBs found in the pooled serum of convalescent patients or vaccinees that bound to the wild-type HBsAg did not bind to the variant antigen at all, indicating that the altered antigenicity of the variant $\mathrm{HBsAg}$ would result in escape in the majority of subjects and was not peculiar to the immune response of the child in question. The monoclonal antibodies used in this study have been shown to identify four distinct epitopes and two overlapping epitopes of the common "a" determinant of $\mathrm{HBsAg}$ and all of these were altered in the natural and recombinant variant antigen. The epitope recognized by one of these antibodies, RFHBs 1 , has been shown to be important in the protective response to HBV and was completely destroyed by the mutation present in this variant HBs protein.

The immunogenicity of the HBsAg was also altered by this single amino acid change. The total anti-HBs titer to the native $\mathrm{HBsAg}$ raised by the variant was 100 -fold lower in mice although a high antibody titer to the homologous antigen was raised. These results give support to the suggestion that this mutation arose as the result of immune pressure.

The importance of this variant remains to be ascertained. Since it evades the immune response elicited after natural infection (convalescent sera) and after vaccination, the potential for spread is present. Whether this is occurring can only be determined by further epidemiological studies. The child infected with this virus became a chronic carrier suggesting that the variant is infectious from cell to cell within the host. The mother did not have the variant virus so the ability of the vari- ant virus to infect a new host has to be formally demonstrated in animal experiments.

\section{References}

1. Le Bouvier, G. H., R. H. Capper, A. E. Williams, M. Pelletier, and A. J. Katz. 1976. Concurrently circulating hepatitis B surface antigen and heterotypic anti-HBs antibody. J. Immunol. 117:2262-2264.

2. Koziol, D. E., H. J. Alter, J. P. Kirchner, and P. V. Holland. 1976. The development of $\mathrm{HBsAg}$ positive hepatitis despite the previous existence of antibody to HBsAg. J. Immunol. 117:2260-2262.

3. Szmuness, W., C. E. Stevens, E. J. Harley, E. A. Zang, W. R. Oleszko, D. C. William, R. Sadovsky, J. M. Morrison, and A. Kellner. 1980. Hepatitis B vaccine. Demonstration of efficacy in a controlled clinical trial in a high-risk population in the United States. N. Engl. J. Med. 303:833-841.

4. Jilg, W., B. Lorbeer, H. Schmidt, B. Wilske, G. Zoulek, and F. Deinhardt. 1984. Clinical evaluation of a recombinant hepatitis B vaccine. Lancet. i:11741175.

5. Wands, J. R., E. Ben-Porath, and E. A. Wong. 1984. Monoclonal antibodies and hepatitis B: a new perspective using highly sensitive and specific radioimmunoassays. In Viral Hepatitis and Liver Disease. G. N. Vyas, J. L. Dienstag, and J. H. Hoofnagle, editors. Grune \& Stratton, Inc., New York. 543-559.

6. Imai, M., A. Gotoh, K. Nishioka, S. Kurashina, Y. Miyakawa, and M. Mayumi. 1974. Antigenicity of reduced and alkylated Australia antigen. J. Immunol. 112:416-449.

7. Mishiro, S., M. Imai, K. Takahashi, A. Machido, T. Gotando, Y. Miyakawa, and M. Mayumi. 1980. A 49,000 dalton polypeptide bearing all antigenic determinants and full immunogenicity of $22 \mathrm{~nm}$ hepatitis B surface antigen particles. J. Immunol. 124:1589-1593.

8. Ashton-Rickardt, P. G., and K. Murray. 1989. Mutants of the Hepatitis B virus surface antigen that define some antigenically essential residues in the immunodominant 'a' region. J. Med. Virol. 29:196-203.

9. Zanetti, A. R., E. Tanzi, G. Manzillo, G. Maio, C. Sbreglia, N. Caporaso, H. Thomas, and A. J. Zuckerman. 1988. Hepatitis B variant in Europe. (Letter). Lancet. ii:1132-1133.

10. Carman, W. F., A. R. Zanetti, P. Karayiannis, J. A. Waters, G. Manzillo, E. Tanzi, A. J. Zuckerman, and H. C. Thomas. 1990. Vaccine-induced escape mutant of hepatitis B virus. Lancet. 336:325-329.

11. Waters, J. A., S. E. Brown, M. W. Steward, C. R. Howard, and H. C. Thomas. 1991. Analysis of the antigenic epitopes of hepatitis B surface antigen involved in the induction of a protective antibody response. Viral Res. 22:1-12.

12. Iwarson, S., E. Tabor, H. C. Thomas, A. H. Goodall, J. A. Waters, P. Snoy, J. Wai-Kuo Shih, and R. J. Gerety. 1985. Neutralisation of hepatitis B virus infectivity by a murine monoclonal antibody: an experimental study in the chimpanzee. J. Med. Virol. 16:89-95.

13. Harford, N., T. Cabezon, M. Crabeel, E. Simeon, A. Rutgers, and M. De Wilde. 1983. Expression of Hepatitis B surface antigen in yeast. Dev. Biol. Stand. 54:125-130.

14. Harford, N., T. Cabezon, B. Colau, A.-M. Delisse, T. Rutgers, and M. De Wilde. 1987. Construction and characterisation of a Saccharomyces cerevisiae strain (RIT 4376) expressing Hepatitis B surface antigen. Postgrad. Med. J. 63(Suppl. 2):65-70.

15. Van Wijnendaele, F., and G. Simonet. 1987. Method for the isolation and purification of Hepatitis B surface antigen using polysorbate. United States Patent No. 4,649,192.

16. Warngsler, D. E., E. D. Lehman, J. Boger, W. J. McAleer, and E. M. Scolnick. 1985. Multiple chemical forms of Hepatitis B surface antigen produced in yeast. Proc. Natl. Acad. Sci. USA. 82:6830-6834.

17. Hauser, P., H. C. Thomas, J. Waters, E. Simeon, P. Voet, M. De Wilde, J. Stephenne, and J. Petre. 1988. Induction of neutralizing antibodies in chimpanzees and in humans by a recombinant yeast-derived hepatitis B surface antigen particle. In Viral Hepatitis and Liver Disease. A. J. Zuckerman, editor. Alan R. Liss, Inc., New York. 1031-1037. 